\title{
The Research on Service Outsourcing Cities Undertaking Ability Relative Efficiency
}

\author{
WANG shengjin \\ Wuhan Textile University, PR. China, \\ EMAIL:57445037@qq.com
}

\begin{abstract}
China Service outsourcing has developed rapidly, demonstration city construct significant results ,industry developed rapidly, the competitiveness is enhancing gradually.the Data envelopment analysis (dea) has the advantages of multiple input and output decision-making. Through 21 service outsourcing demonstration city of relative efficiency, found o service outsourcing city undertaking relative efficiency is generally low, and there exists a significant difference between different cities, Most demonstration cities all have different inputs and outputs of redundancy or insufficient output. Outsourcing cities must position accuratly its industry, the rational allocation inputs, and continuously adjust and optimize to the optimal.
\end{abstract}

Keywords: service outsourcing, DEA model, relative efficiency

\section{Introduction}

Since 2006 years, China's service outsourcing industry develop rapidly under a series of policies. The scale of the industry continues to expand, the structure constantly continuous optimizate, the capability of independent innovation constantly enhance, the high added value services continues to increase,the delivery centre face forword to the globalization.The international competitiveness of service outsourcing industry is gradually narrowing the distance between international well-known outsourcing city. "China's service" brand's international influence has appeared. As a key services trade the modern service industry, service outsourcing plays an important role in the adjustment of economic structure, to transformate the mode of foreign trade development and promote the employment of university students, etc..According to the Ministry of Commerce statistics, China's undertaking service outsourcing contracts was 167,424 copies, amount $\$ 95,49$ billion in 2013, was 4.77 times in 2009, an average annual growth rate is $47.8 \%$; The execution contract amount increased from $\$ 20.01$ to $\$ 63.85$ billion, an average annual growth rate was 59\%. Among them, the 2013 international service outsourcing contract amount was $\$ 62.34$ billion, a the growth rate was $42.2 \%$ in 2013; The implementation amount was $\$ 45.41$ billion, the growth rate was 35\%.By the end of 2013, China had service outsourcing enterprise 24,818 , in all, nationwide 115 cities, employed up to 5.361 million.
Beijing, Shanghai and other 21 service outsourcing demonstration cities had made remarkable achievements, the industry growed rapidly. The competitiveness of the industrial level continuously improve, the development environment changed perfect, the demonstration leading role $\mathrm{c}$ onstantly enhance.The main industry development index increase more than average level of the country, the contribution degree of international service outsourcing contract execution amount is up to $95 \%$. The demonstration city has becomed the core strength of leading China's international service outsourcing development.National service outsourcing "twelfth fiveyear" plan put forward in the future to continue to play the leading role of the China service outsourcing demonstration city, and promoted the domestic gradient transfer of international service outsourcing industry, promote the coordinated development and linkage of the eastern and western regions.

In recent years, more and more scholars researched the undertaking service outsourcing efficiency between the demonstration cities'and competitiveness in the kinds multi-directional exploration. Wang Wei (2013) using the standard deviation method evaluate the 21 service outsourcing demonstration city competitiveness, think of each demonstration cities should play the local comparative advantage of service outsourcing; $\mathrm{He} \mathrm{Wu}$ (2011)set an evaluation index system of service outsourcing undertaking competition ability by the method of principal component analysis, the quantitative analysis that regional industry cluster advantage of service outsourcing demonstration has important influence to city comprehensive competitive advantage. The dislocation development, the industrial clusters of regional integration is the only way for the development of service outsourcing in China; Zhang Ying (2013) synthetically used the SPSS factor analysis method and entropy method, proposed that Anhui should start from improving the macro environment, to develop the service outsourcing industry; $\mathrm{Su} \mathrm{Na} \mathrm{(2013)} \mathrm{based} \mathrm{on} \mathrm{the} \mathrm{diamond}$ model, used the multiple regression analysis and principal component analysis method, researched the service outsourcing development from the vertical in Jiangsu province, think that the key to maintain service outsourcing competitiveness is not to cling to the labor cost advantage, but to improve the quality of human resources, the infrastructure construction and other factors; Niu Zhongyang (2014) researched our country's financial services outsourcing through the Logistic model, think that human resource level and policy support and other factors of enterprise play a positive role in the 
outsourcing decision of financial institutions, the dependence, the protection of intellectual property rights and other factors Will play a role of reverse in the outsourcing decision process.

The above scholars provided a certain research basis for the competitiveness evaluation system of offshore service outsourcing city. but the more studied from different angles and sections, also the parameters will have a lot of heavy subjective factors in the process of building a mathematical model, lack of the authority of the latest data,so it is difficult to meet the needs of the rapid development of service outsourcing industry theoretical guidance. In this paper, we using the advantage that DEA does not need to estimate parameters in advance, and the other simplified algorithms and reduce error, study the relative efficiency of offshore acceptance capability for 21 service outsourcing demonstration city in China used DEA method.

\section{Text}

The DEA method also known as data envelopment analysis (Data Envelopment Analysis), it is the non parametric method of relative performance for an evaluation developed (Decision Making Unit, DMU) of the relative efficiency of decision making units concept by the famous A.Charnes and W.W.Cooper operational research experts. Model based on comprehensive analysis of input and output data, with the help of mathematical programming put the DMU projection to the DEA frontier, and by comparing the deviation from the frontier of decision making unit DEA to evaluate their relative effectiveness, concluded that the comprehensive efficiency of each decision-making unit index, According to this each decision-making unit grading queuing, determine the effective decision making units. At the same time can give the others the reason and degree of decision making units not effective, provides management information to decision makers. Due to the DEA method do not need to anticipate the advantage of parameters in the research of multiple input, multiple output production function theory, so it has incalculable advantages in simplified algorithm and reduce the error. This paper used the most typical. $\mathrm{C}^{2} \mathrm{R}$ model to evaluate .

\subsection{DEA evaluation index system}

\subsubsection{The principle of evaluation index selection}

The process of efficiency evaluation in DEA method, it is a key and important issue that scientific and reasonable set up the evaluation index system, the selected indexes must reflect comprehensive, systematic, scientific and reasonable evaluation for the main input and output situation .

1.The systematic principle

In the selection of input and output index must pay attention to extracting and comparing the index system for comprehensive, full range, efficiency problems reflect the evaluation of different subjects.

2.The scientific principle

The selection and design of the evaluation index system must be scientific and reasonable, must reflects the objective and true evaluation subject of input and output situation, to make a reasonable combing around the theme demonstration and selection in numerous evaluation index, avoid duplicate and invalid selection.

3.The principle of standardization

When choose and design the index system, should as far as possible standardization and internationalization, to meet the requirements of data model. To focus on the reality conditions in practical application, easy to obtain comparative and data, simple operation and analysis.

2.2.2.The evaluation index system of service outsourcing demonstration cities

The evaluation index system is divided into two parts, one is the input index system, and another is the output index system. For the offshore service outsourcing, part of the input index system can use count the number all model service outsourcing cities service outsourcing enterprises (X1) number of employees (X2), number of colleges and universities (X3), the number of Internet users (X4) to characterize in the end of 2012; output indicator system can total offshore contracts through the city (Y1), offshore execution amount of the contract (Y2) to reflect. See table 1-China service outsourcing demonstration city input and output index system table.Because Unable to obtain the accurate data of Changsha offshore service outsourcing, so do not be evaluated. 
Table 2 Calculated results of the model

\begin{tabular}{lllllllll}
\hline Number & (DMU) & $s_{1}^{-}$ & $s_{2}^{-}$ & $s_{3}^{-}$ & $s_{4}^{-}$ & $s_{1}^{+}$ & $s_{2}^{+}$ & $\theta$ \\
\hline 1 & Beijing & 0.000 & 0.000 & 0.000 & 0.000 & 0.000 & 0.000 & 1.000 \\
\hline 2 & Tianjin & 0.000 & 0.000 & 21.016 & 48.389 & 0.000 & 0.315 & 0.490 \\
\hline 3 & Shanghai & 0.000 & 0.000 & 15.561 & 123.383 & 13.682 & 0.000 & 0.808 \\
\hline 4 & Chongqing & 0.000 & 0.365 & 12.127 & 0.000 & 1.697 & 0.000 & 0.293 \\
\hline 5 & Dalian & 64.513 & 0.383 & 10.726 & 0.000 & 0.946 & 0.000 & 0.527 \\
\hline 6 & Shenzhen & 0.000 & 0.000 & 0.000 & 0.000 & 0.000 & 0.000 & 1.000 \\
\hline 7 & Guangzhou & 0.000 & 4.836 & 3.149 & 143.132 & 2.375 & 0.000 & 0.831 \\
\hline 8 & Wuhan & 0.000 & 0.100 & 17.739 & 45.997 & 0.000 & 0.979 & 0.355 \\
\hline 9 & Harbin & 0.000 & 0.000 & 16.428 & 19.336 & 0.000 & 1.288 & 0.491 \\
\hline 10 & Chengdu & 0.000 & 0.000 & 3.853 & 1.602 & 0.000 & 0.160 & 0.416 \\
\hline 11 & Nanjing & 0.000 & 3.065 & 18.624 & 0.000 & 5.591 & 0.000 & 0.604 \\
\hline 12 & Xian & 0.000 & 0.343 & 8.374 & 0.000 & 1.290 & 0.000 & 0.232 \\
\hline 13 & Jiman & 0.000 & 3.376 & 27.467 & 0.000 & 0.000 & 0.141 & 0.554 \\
\hline 14 & Hangzhou & 0.000 & 4.533 & 9.412 & 0.000 & 2.564 & 0.000 & 0.845 \\
\hline 15 & Hefei & 0.000 & 0.187 & 20.146 & 0.000 & 0.000 & 0.023 & 0.424 \\
\hline 16 & Nanchang & 40.466 & 0.648 & 8.677 & 0.000 & 0.000 & 0.284 & 0.229 \\
\hline 17 & Daqing & 177.747 & 0.000 & 3.559 & 9.395 & 0.028 & 0.000 & 0.653 \\
\hline 18 & Suzhou & 351.983 & 0.000 & 6.935 & 39.138 & 0.000 & 1.138 & 0.683 \\
\hline 19 & Wuxi & 0.000 & 0.000 & 0.000 & 0.000 & 0.000 & 0.000 & 1.000 \\
\hline 20 & Xiamen & 48.073 & 0.000 & 4.451 & 20.752 & 0.078 & 0.000 & 0.349 \\
\hline
\end{tabular}

\subsection{The result analysis}

We can see From the tablein the 20 national service outsourcing demonstration cities, only Beijing, Shenzhen, Wuxi and other three cities DEA is effectively, other 17 cities such as tianjin rendered DEA is invalid, the efficiency is only $15 \%$.City of offshore service outsourcing to undertake relative efficiency is generally low, and there exists a significant difference between different cities, different cities have different inputs and outputs redundancy, and insufficient output.

2.2.1.Beijing and other 3 cities includes not only on technical efficiency effectively, and on the scale efficiency is the best, all kinds of resources are fully utilized, to obtain the output results of the largest.Five cities such as dalian, nanchang, xiamen service outsourcing enterprises quantity have input redundancy; 9 cities such as chongqing, dalian, nanchang have input redundancy;in addition to the three effective cities university number in 17 cities all show input redundancy; 9 cities such as tianjin, Shanghai Internet users input redundancy;All the effective demonstration cities have different levels of insufficient output.

2.2.2.From table 2 , third and fourth columns can be seen the slack variable quantity is zero of most service outsourcing enterprises and practitioners, It can be seen that most representative demonstration environment is suitable for outsourcing industry development, industry development environment can support offshore inputoutput efficiency to achieve the optimal package. Namely, without changing the existing industry under the situation of environmental input by other input factors to improve and enhance, can achieve the optimal efficiency. And input redundancy city may have been small scale enterprises, output is not high and lead to efficiency is not made to achieve optimal.
2.2.3.The number of colleges and universities, On behalf of the human resources support and quality column shows that most of the cities in the input are redundant. That most of the cities of the colleges and universities lack the offshore service outsourcing talents training, or is to cultivate the talent quality is not high and cause of redundancy。

2.2.4.The technology and the network basic factors of the sixth column indicates that our country existing network environment and the technology is efficiency now, most achieves optimal, but to continue to develop service outsourcing, will continue to increase budgetary allocations for this work.

\section{Conclusion}

The effectiveness of the offshore service outsourcing undertaking ability has nothing to do with city's economic development area.Depends on the rational allocation between the input factors of the city development, associated with urban industrial structure upgrading, Correct evaluation of city advantage and potential, accurate positioning of the city of industry, accurate positioning of the city industry, the adjustment of urban economic factor input structure, continued to promote industrial upgrading, this Is the right way to improve urban economic development effectiveness.So each service outsourcing cities should have a correct understanding and evaluation for the input factors and the level of industrial development, adjust measures to local conditions, to create a good environment for local industrial development, personoriented, independentinnovation, the serviceoutsourcing $i$ ndustry has become new power of economic development in the region. 


\section{References}

[1] Wei Quanling. Evaluation of DEA relative efficiency method of operations research new area [M]. Beijing: Renmin University of China press, 1998

[2] Wei Quanling. Data envelopment analysis [M]. Beijing: Science Press, 2004.

[3] Wang Wei, Zhang Jianye, Qi Xiuhui. China's service outsourcing demonstration city competitiveness research -- Analysis Based on the combination of three methods of Kendall coefficient. Study on the management of science and technology, 2013,33 (14); 86

[4] he $\mathrm{Wu}$. Analysis of the competitiveness of Chinese service outsourcing demonstration city. Statistics and decision, 2011, (15); 97-99

[5]Zhang Ying. Research on path in Anhui province and the development of service outsourcing industry competitiveness -- a comparative analysis

based on the Yangtze River Delta 10 city of service outsourcing competitiveness. East China economic management, 2013,27 (6); 